\title{
INFORMATION ETHICS IN THE TWENTY FIRST CENTURY
}

\author{
Paul Sturges \\ Published in Australian Academic \& Research Libraries, 40(4), 2009 pp.241-251
}

\section{INTRODUCTION}

The discourse of practitioners in the domain of information science has been changing fundamentally in the last decade. The author's contention is that its centre has shifted from a predominant concern with technique (starting with topics like acquisitions and moving through cataloguing and conservation to user education and beyond), towards engagement with a range of issues (such as intellectual property, user privacy, and serving the socially excluded) in which the ethical dimension predominates. Of course, it would take something such as a major analysis of the information science literature to confirm or deny this proposition. This analysis would be difficult because the greatest volume of professional communication (printed, electronic and spoken) is overtly technical and will remain so, and the literature of theory still sets out to discuss information as a scientific phenomenon, rather than a product of moral action. However, to accept the evidence of titles would lead to an underestimate of the extent to which the literature contains ethical discussion in documents that do not ostensibly deal with ethics. Therefore this paper asks the reader, for the sake of argument, to accept the proposition that the centre of gravity (if not the volume) of the literature of practice, the content of professional conferences, seminars and workshops, and much of the everyday exchange of information and ideas between professionals is in the process of shifting. What follows is quite simply a sampling and rationale designed to flesh out the proposition that twenty first century information science is becoming ethical information science. The proposition will still remain unproven by the end of this paper, but the reasons for suggesting it should at least be clear.

First, however, it is necessary to make the point that information ethics is not the exclusive possession of the discipline of information science. It is very easy to identify a grouping of domains that are distinct in themselves but nevertheless share a concern with an overlapping set of ethical problems. All of these can be seen as contributors to a broader information ethics. Discussion of information ethics in the discourse of information science has tended to grow out of discussion of the ethics of librarianship. But media and press ethics, computer and Internet ethics, and also the ethics of governance and business concern themselves with, amongst other issues, most of the same ground as the ethics of librarianship. This professional convergence, driven by the growth of Internet and digital access, shifts emphasis, but there is a core of intellectual freedom issues, privacy and secrecy, concerns with social equity and justice and matters of the ownership of information that show differing faces across all of the domains. The only one of these areas that may not seem obvious at first glance is the ethics of governance and business, but in fact the tension between the disclosure or sharing of information is at their moral heart. There is a central dialogue concerning what the holders of political and economic power genuinely need to conceal and what they should be obliged to disclose to society at large in the interests of individual welfare and social good. 
It is the sheer breadth and inclusiveness of information ethics that makes it an exciting area. Yet the curious fact is that specialists in the various domains tend to conduct a set of parallel conversations on information ethics that intersect surprisingly infrequently. This paper will make some ventures across the invisible and unhelpful boundaries between these professional discourses in pursuit of a more complete discipline of information ethics. These ventures will be mainly in relation to the codes of ethics and professional practice and other formal statements from associations and societies that are the most public expression of the state of ethical reflection in the professions. The paper will continue with a necessarily short excursion into the extensive professional literature, not neglecting the significant web resources that now complement the print documentation. Conferences, seminars and other professional gatherings, education and training in information science and continuing professional development programmes will be the final aspect discussed.

\section{CODES, MANIFESTOS AND CHARTERS}

The reason for discussing the formal documentation of information ethics first is precisely because these statements are the public face that the professions adopt in relation to ethical concerns. A set of essays edited by Vaagan (2002), although its title suggests a broader remit, is very much about codes of ethics. A careful read can tell us a great deal about the global situation at the beginning of the decade. It is fairly common to talk of codes as though they are the basis of a system of discipline for professionals. Although this is often the way they are presented, only the few professions that routinely handle matters of life, death and big sums of money (doctors, lawyers and accountants) are able to operate an effective disciplinary system based on their code of ethics. The code in virtually every other case is aspirational, inspirational and a basis for ethical reflection. In a code, the profession tells its members what they should consider when faced with an ethical dilemma, whilst demonstrating to a wider audience that the profession does not leave its members devoid of good guidance. As short statements of principle, codes can seldom provide everything that is needed to cope with the moral ambiguities that are the stuff of professional life. In the end a professional makes a decision that may, or may not derive directly from the principles laid down in a code. Because the nature of the dilemmas experienced by members of different professions varies, the codes vary too, but a brief look at a sample will indicate that there is commonality as well as singularity.

Journalists quite clearly support the same ultimate aims (access to information) as LIS professionals. Half of the Code of Ethics of the Society of Professional Journalists (www.spj.org/ethicscode.asp ) falls under the heading 'Seek the Truth and Report It'. Amongst other topics it deals with accuracy, balance, citing sources (when possible), avoidance of plagiarism, representation of minority and marginalised views, and encouraging open government and access to official information. Similarly, the American Society of Newspaper Editors' Statement of Principles (www.asne.org/kiosk/archive/principl.htm ) takes as its starting point the First Amendment to the American Constitution, and stresses freedom, responsibility, independence, truthfulness, impartiality and fairness of the press. On the other hand, in the field of computing, the widely-quoted Association for Computing Machinery's 
Code of Ethics and Professional Conduct (www.acm.org/about/code-of-ethics ) has information-related clauses, but on intellectual property rights, privacy and confidentiality. The difference of approach is obvious. Somewhat similarly, the Society of Internet Professionals (www.sipgroup.org/sip/code.html ) emphasises privacy and confidentiality, the avoidance of pornography and other 'harmful' content and the prevention of spam. In the business field, the emphasis is similar, the Chartered Management Institute's Code of Professional Conduct and Practice www.managers.org.uk/doc_docs/Code_of_Professional_Conduct_And_Practice.pdf also places a high value on confidentiality and also encourages exhausting internal procedures before public disclosure (whistleblowing) of suspected business impropriety. Lastly, and in some ways most interestingly, the Society of Competitive Information Professionals' Code of Ethics (www.scipstore.org/2_code.php ) is short and more or less totally concerned with restraining its members from breaking the law, let alone subtler ethical values, in their pursuit of information for the benefit of their employers. What we see from this tiny sample from all the easily available codes is a fascinating range of different emphases concerning ethical conduct relating to information, depending on the professional orientation of those concerned.

There are also national differences, rooted in culture and history (Sturges, 2003). A glance at a few fairly recent codes for librarians (www.ifla.org/faife/ethics/codes.htm) from France, 2003; Italy, 1997; the Netherlands, 1993; Portugal, 1999; and Switzerland, 1998, suggests that a user/profession/collection approach can be identified as a common method of organising the content of a code. The French code, for instance, begins with nine statements about users, beginning with 'Respecter tous les usagers' (Respect all users) and ending with 'Promouvoir auprès de l'usager une conception de la bibliothèque ouverte, tolérante, conviviale' (Promote the idea of an open, tolerant and friendly library to users). A section on the profession is common as balance to this, with statements such 2.1 from the Italian code, which translates as 'The librarian shall honour the profession, profoundly aware of its social usefulness'. These two groups of statements are then often placed in balance by a section on the collection. Both the Italian and French codes have each of these three elements. But different approaches to the same principles can also be found. The Netherlands code contains statements on the collection, such as 'The librarian builds up a collection and preserves it, according to the information and media needs of users, and the role of the library within the community.'

Furthermore, to talk simply of a user/profession/collection approach to a code would clearly not fully characterise codes that have these elements. The French code, for instance has an extremely interesting fourth element - 'La tutelle'. According to the dictionaries, the word translates into English as 'guardianship', but that definitely fails to catch the flavour of the section, which actually seeks to place the librarian's responsibilities in an organisational and policy context. Amongst other things this section is able to deal in a subtle and convincing way with the political and other pressures which librarians might experience. In other codes a rights-based approach can be distinguished. The Portuguese code, which incidentally offers a disciplinary structure in its preamble, exemplifies this approach. Its content is divided between Intellectual Freedom, User Privacy and Professionalism. The latter is long, containing 24 clauses and moves from professional competence, through (amongst other topics) relations with users and continuing professional development to sharing professional knowledge. The Swiss code is different again, offering a more purely professional 
view of the duties and rights of the librarian. Collections, access, education and training ('formation' in the French) and responsibility (which includes confidentiality and avoidance of bias) are the larger headings.

In addition to codes of ethics, we should look at other formal policy documentation described by such names as 'declaration', 'charter' or 'manifesto'. For instance the African Conference on Information Ethics, held at Pretoria in 2007, issued a 'Tshwane Declaration on Information Ethics in Africa' (http://www.africaininfoethics.org/tshwanedeclaration.html). The academics attending the conference reaffirmed the information rights in the Universal Declaration of Human Rights, stressing the value of information in society and calling for equality of access. The distinctively African aspect to the Declaration was its stress on indigenous knowledge and cultural diversity. Whether such isolated statements from academic conferences are capable of exercising influence is debateable. Rather more to the point are the efforts of established institutions with a continuing presence. For instance, the Association for Progressive Communications' Internet Rights Charter http://rights.apc.org/charter.shtml deals with seven themes: universal access to Internet, freedom of expression and access to knowledge, sharing of knowledge through open source, privacy and surveillance, Internet governance and protection of rights in the context of Internet. The breadth and directness of this is valuable and promises a useful future for the Charter.

Documents can also be more narrowly-focused as the creation of a manifesto for IFLA illustrates. Over the period 2006-8 FAIFE carried out a policy-making process, on behalf of IFLA, that it was hoped would be a good exemplar for the profession. This began when the Croatian Library Association agreed to link a FAIFE short conference on libraries and the struggle against corruption with its annual freedom of expression seminar in December 2006. Papers from FAIFE, CLA and Transparency International speakers were followed by substantial debate. The outcomes from the conference included a 'shopping list' of points that might form part of an IFLA policy document. This list was used as a basis for a second event in August 2007 held in partnership with the Goethe Institute and LIASA (South Africa's library association) as a WLIC pre-conference in Johannesburg. The outlines of a Manifesto on Libraries and Transparency, Good Governance, and Freedom from Corruption were developed on the basis of the papers and discussions at the pre-conference, and after several drafts, the obtaining of expert opinion, and re-drafts the Manifesto was accepted by the Governing Board in 2008 and is now IFLA policy (www.ifla.org/ll1/misc/transparencymanif.htm).

\section{THE LITERATURE}

The relevant literature includes hardly any monograph-type material, but much more by way of journal articles, and web content. The lack of monograph writing is clearly indicative of a still immature sub-discipline. The philosophy of information is the obvious route towards substantial treatments of the ethical aspect of information. Luciano Floridi has published substantial work on the philosophy of information and has made significant statements on ethics which promise quite soon to amount to monograph-style treatment of the topic. A book chapter like Floridi (2008) gives an indication of the way he looks at information ethics. Likewise, Rafael Capurro is a 
philosopher of information first and then a contributor to information ethics as a natural development of his philosophical explorations. Again, as example only, one could look at an article (Capurro, 2006) in which he offers a different philosophical basis for the information ethics from that developed by Floridi.

All in all, it would not be unreasonable to describe the bulk of literature of information ethics as having fairly recent roots (from the mid 1970s at least); about 15 years of some growth at the end of the twentieth century; and a decade of quite rapid growth in the first decade of the twenty first century. From a librarianship point-ofview, the literature could be said to have been offered a shape as early as the very striking paper by Hauptman (1976) in which he described posing as a potential arsonist in libraries and being given material on bomb-making virtually without question. Although described as 'deeply unscientific' by at least one commentator, the paper nevertheless had the enormous value of challenging the library profession to reexamine its value-free ethic of service. In the age of the USA PATRIOT Act, and disturbing levels of official interest in identifying possible terrorists through their library use, Hauptman's paper seems to come from a different world, rather than merely a different century. Generally, information ethics can be said to have taken shape much more recently. For instance, the key paper in computer ethics seems to have been Moor (1985) in which the three aspects of logical malleability, social impact, and invisibility are used to outline a distinctive sub-discipline. It still repays reading.

A good indication of the development of the field is obtained by looking at the small but expanding text book literature. Some of the best text books do describe themselves as being about Information Ethics, but others are labelled as concerning Computing or Information Technology Ethics. It is probably not surprising that there isn't an outstanding text book on the ethics of librarianship, since Computer Science has a market of hundreds of thousands of students worldwide, but Library and Information Science scarcely tens of thousands. Examples of computer ethics based text books illustrate their strengths and weaknesses. Forester and Morrison $\left(2^{\text {nd }} \mathrm{ed}\right.$ 1994) is easy to read and anecdotal, but its coverage of computer crime, software theft, hacking, systems failure, privacy, artificial intelligence and workplace issues, has a great deal to say to librarians. What is more, its stories come from all over the world. Severson (1997) attempts to build a system for ethical practice, but his concentration on intellectual property, privacy and what he calls non-maleficence, seems jejune. Reynolds (2003) is highly structured in a way that allows it to be used as the main content of a module of instruction. It covers basically the same wider ground as Forester and Morrison, but its content is much more exclusively American. Duquenoy, Jones, and Blundell (2008), whilst describing itself as being about professional responsibility in the computer industry has an international range and significance beyond computing as such. A module on ethics for librarianship in the digital age can make very good use of these and others for explanation, case studies and exercises. Books specifically dealing with librarianship are also on the shelves. Lindsey and Prentice (1985) and Hauptman (1988) began to use text book format to define the ethics of librarianship in the mid 80 s, but do not wholly convince. Hauptman (2002) has revisited the area more recently, and Buchanan and Henderson (2009) has just appeared. There is a case for saying that only for specifically library management content is there much need to turn to textbooks such as these. 
Article-length literature is found across a wide range of journals, which makes it rather difficult to assess its quantity. The fact that there are one or two specialist information ethics journals helps. Robert Hauptman's Journal of Information Ethics, founded in 1992, brings together a rich and fascinating mixture of articles that perfectly illustrates the breadth of the field. As an electronic journal, the International Review of Information Ethics is well-positioned to publish swiftly and eclectically. Ethics and Information Technology, founded 1999, encourages a wide range of content and is also hospitable to LIS articles. A collection of relevant articles in a general LIS journal, such as that edited by Carbo and Smith (2008) is welcome, particularly since the collection includes a bibliography on information ethics assembled by Toni Carbo, David Perrotta, Jeffrey Neher, and Martha Smith. In addition, as suggested in the Introduction to this paper, the twenty first century literature is much more concerned with ethical issues than it might seem on the surface. For instance, Liew (2009) in a survey of research on digital libraries identifies only about a dozen articles, from just over 90 discussed, as concerning ethical topics. However, many of the other articles concerning aspects such as usability, copyright, regulatory issues, socio-cultural or economic issues, are laden with ethical content. Liew's comment on papers concerned with ethics that 'This perhaps highlights an area for further research as these issues gain importance along with the growth and development of DLs' (p254) is positive, but probably underestimates the existing level of activity.

Web content is also to be expected and is to be found across many discussion lists and blogs dealing with topics such as intellectual property, privacy and censorship. Much of this is brief comment on the issues of the day, but two contributions of a more substantial nature should be noted. The International Center for Information Ethics (ICIE), http://icie.zkm.de hosted in Karlsruhe, Germany, and managed by Rafael Capurro describes itself as 'an academic website on information ethics' and 'a platform for exchanging information about worldwide teaching and research in our field'. The website provides substantial listings of relevant publications, is associated with a book series jointly published with W. Fink Verlag, and since 2004 ICIE has published the International Review of Information Ethics, mentioned above. The website of CILIP (the UK's LIS association) provides the Institute's own Ethical Principles and Code of Professional Practice, but also leads to a semi-independent Information Ethics website www.inforethics.org.uk, which is a joint initiative with InfoResponse Associates and Oxford Business Intelligence. For those looking for an extremely full set of resources, with an interdisciplinary dimension, this site can be strongly recommended. A particularly useful feature is a set of over 40 easily accessed case studies, to which users are invited to submit new examples.

\section{CONFERENCES, EDUCATION AND TRAINING}

One of the key ways to recognise an emerging discipline, or sub discipline, is through its visibility at professional and academic conferences. In the early years, that will tend to consist of isolated papers, followed in time by sessions bringing together a small number of related papers, and then whole sub-themes. LIDA itself was a case in point in 2001 with its sub-theme 'Internet: Ethics and Legal Issues', which this paper celebrates by reviewing the current state-of-the-art. Names mentioned elsewhere in this paper, such as Capurro, Froelich and Koehler were invited speakers at Dubrovnik 
in 2001. Topics that they and other speakers covered included digital libraries, journalism, privacy, social equity and censorship. Although quite a number of other conferences had had similar themes and sub-themes during the 1990s, LIDA was still quite an early contributor and already there was a good deal of lively discussion about the emerging shape of the sub-discipline. In fact, two distinguished invited speakers were almost left on the Korcula ferry, so deep was their discussion on some ethical niceties, and so unaware were they that everyone else had disembarked.

UNESCO has given information ethics a kind of stamp of approval in the form of INFOethics conferences of invited experts and other significant players in 1997, 1998 and 2000. These have been followed up by regional conferences on Ethical Dimensions of the Information Society (Latin America in 2006, Africa in 2007 and Europe later in 2007). Finally, the World Summit on the Information Society, facilitated by UNESCO, includes Action Line C10 'Ethical Dimensions of the Information Society', which is being followed up by organisations such as IFLA. The oldest-established and most frequent information ethics conference is ETHICOMP, which began in Leicester, UK, in 1995. The organisers have worked in cooperation with another (more theoretical) conference - CEPE, Computer Ethics: Philosophical Enquiry - to provide a forum for computer-related information ethics discussion for most years in well over a decade. The 'Ethics of Electronic Information in the 21st Century' symposia, held at the University of Memphis, have produced some useful evidence of their quality in the forms of volumes of essays based on the conference content, for instance Rockenbach and Mendina (2003) which doubled as a festschrift for Stephen Almagno. Lastly in this incomplete survey of conferences, the ICIE has been responsible for two excellent symposia with a long list of invited experts, at Karlsruhe, Germany, in 2004, and Pretoria, South Africa in 2007.

Turning to education in information ethics, assessing its extent is frustrating. The presence, or absence, of information ethics in academic curricula is not completely obvious. The problem is that there is certainly a substantial commitment to the teaching of information ethics, but very often concealed within modules on management or information in society. At Loughborough University, UK, for instance, the author and colleagues have taught information ethics under the guise of 'Legal and Professional Issues' and related titles for at least twenty years. These modules are basically issues-driven and cover the essential topics such as intellectual freedom, privacy, intellectual property, and Internet management. Looking for information ethics in curricula is probably easiest if one is able to follow the names of contributors to the relevant literature to their home institutions. Thus the University of Pittsburgh immediately emerges as a significant centre, because of the work of Toni Carbo and colleagues. One of the few published treatments of information ethics in curricula is in fact Carbo (2008). Other significant concentrations would also include the following. At the University of Wisconsin-Milwaukee, Johannes Britz has fostered teaching and research in the ethics field and this has involved visiting professorships for luminaries such as Rafael Capurro and Peter Lor (IFLA's former General). Veteran American contributors to the field, Thomas Froelich of Kent State University and Wallace Koehler of Valdosta University, have given their institutions a profile. In Canada Toni Samek's work has identified the University of Alberta as a relevant centre, and in the UK Charles Oppenheim and Loughborough University's Legal and Policy Research Group have established a strong commitment. One could easily add to the list. However, the only helpful general conclusion is that you don't 
have to call a module 'Information Ethics' for that to be its core content, and information ethics is also present in small but significant ways across the curriculum.

A casual scan of the advertised training opportunities from professional organizations and training consultancies confirms that they have identified strong demand for ethics-related content. Within IFLA, FAIFE has, since 2005 had the financial means to undertake an extensive and systematic education/CPD programme. The finances form part of a generous grant from Swedish Sida for intellectual freedom activities in the developing world. A tentative beginning at a conference in Costa Rica in the spring of 2007 on the subject of the IFLA/UNESCO Internet Manifesto was an enormous success. It obviously indicated a basis for similar activity in other suitable countries. Mexico was used as a testing ground for the spread of the Workshop activity and it was subsequently extended to Brazil and onwards. It was quite clear that FAIFE had tested out a sustainable educational activity, inspiring and training trainers who could extend the activity through one country's professional community, or take it across frontiers into other countries. Learning materials for Internet Manifesto Workshops were drafted and a second set of materials for Access to HIV/AIDS Information Workshops was added. The rationale for these HIV/AIDS Information materials is that the virus can only be fought completely effectively by the provision of good information; information that library services can partner the health services and health NGOs in providing.

A common style was developed for these two sets of materials, outlining and providing content (including Powerpoint slides) for lectures and interactive learning. They have since been used by FAIFE presenters throughout the developing world. The materials have also been translated into various IFLA languages and used by presenters not directly provided by or financed by FAIFE.

(http://www.ifla.org/faife/news/learning_materials_workshops.htm) In October 2008 FAIFE and IFLA's Health and Biosciences Section outlined materials on Public Access to Health Information materials (to cover information on infectious disease and immunization, diet and nutrition for health, the problem of alcohol and drugs, and the prevention of accidents - traffic accidents in particular). During 2009 the writing and piloting of the materials will be completed. A fourth set of materials based on the Manifesto on Libraries and Transparency, Good Governance and Freedom from Corruption (Transparency for short) were outlined in November 2008. The writing of these materials was completed by the end of the year and they can be found in more than one IFLA language on the IFLA website

(http://www.ifla.org/faife/policy/transparency-learning-material.htm).

\section{CONCLUSIONS}

There is a small but worthwhile conclusion to be drawn from the above. It is that there is a genuine claim that a sub-discipline of information ethics has become well established in the first decade of the Twenty First Century. The interesting question that this raises is 'Sub to what?' Clearly it is sub to Information Science, but since Computer Science, Media Studies and the other disciplines mentioned here do not particularly recognise themselves as partial incarnations of Information Science, that isn't a completely helpful answer. It might be better to say that information ethics is actually one of the few ways in which this broad area actually reveals a unity that 
logic, if not professional practice, suggests. The development of information ethics has been a wholly positive phenomenon, encouraging not only a principled reflection on a host of aspects of information and communication, but also opening up the potential for fruitful cross-disciplinary enquiry and debate. In particular, the sometimes stale professional discourse of librarianship has been enriched by an ethical focus, suggesting that a maturing of professional life is taking place. If, as can be claimed, a mature professional is an ethical profession, library and information work is revealing increasing levels of maturity.

\section{REFERENCES}

Buchanan, E. and Henderson, K. (2009) Case Studies in Library and Information Science Ethics. Jefferson, NC: McFarland.

Capurro, R. (2006) Towards an ontological foundation of information ethics. Ethics and Information Technology 8(4) pp175-186.

Carbo, T. (2008) Ethics education for information professionals. Journal of Library Administration 47(3-4) pp. 5-25.

Carbo, T. and Smith, M. Eds. (2008) Perspectives on Global Information Ethics. Journal of the American Society for Information Science and Technology 59(7) pp.1109-1183.

Duquenoy, P., Jones, S., and Blundell, B. (2008) Ethical, Legal and Professional Issues in Computing. London: Middlesex University Press.

Floridi, L. (2008) Information ethics: its nature and scope. In: Van den Hoven, J. and Weckert, J. Eds. Moral Philosophy and Information Technology. Cambridge: University Press, pp40-65.

Forester, T. and Morrison, P. (1994) Computer Ethics. $2^{\text {nd }}$ ed. Cambridge, Mass: MIT Press.

Hauptman, R. (1976) Professionalism or culpability? An experiment in ethics. Wilson Library Bulletin 5(8) pp626-627.

Hauptman, R. (1988) Ethical Challenges in Librarianship. Phoenix, AZ: Oryx Press.

Hauptman, R. (2002) Ethics and Librarianship. Jefferson, NC: McFarland.

Liew, C.L. (2009) Digital library research 1997-2007: organisational and people issues. Journal of Documentation, 65(2) pp245-266.

Lindsey, J. and Prentice, A. (1985) Professional Ethics and Librarians. Phoenix, AZ: Oryx Press.

Moor, J. (1985) What is computer ethics? Metaphilosophy 16(4), pp266-275. 
Reynolds, G. (2003) Ethics in Information Technology. Boston, Mass: Thomson Course Technology.

Rockenbach, B. and Mendina, T. eds. (2003) Ethics and Electronic Information. Jefferson, NC: McFarland.

Severson, R. (1997) The Principles of Information Ethics. Armonk, NY: M.E. Sharpe.

Sturges, P. (2003) It's not cricket: laws of the game, or guidance in ethical reflection for information professionals in Western Europe. Available at http://www.ifla.org/files/faife/publications/sturges/not-cricket.pdf [Accessed 18.05.10]

Vaagan, R. Ed. (2002) The Ethics of Librarianship: an International Survey. Munich: K.G. Saur. IFLA Publication 101. 